\title{
The Behavior of $\alpha_{2}$-Plasmin Inhibitor in Fibrinolytic States
}

\author{
Nobuo AOKI, MasaAKI Moroi, Michio Matsuda, and Kazuko TachiYa \\ From the Department of Medicine and the Institute of Hematology, Jichi Medical School, \\ Minamikawachi-Machi, Tochigi-ken 329-04, Japan
}

A B S T R A C T Human plasma $\alpha_{2}$-plasmin inhibitor in fibrinolytic states was studied using immunochemical methods and radioiodinated plasminogen. The concentration and activity of plasma $\alpha_{2}$-plasmin inhibitor decreased when urokinase was added to plasma in vitro or infused intravenously in man. The decrease was associated with the appearance of plasmin- $\alpha_{2}$-plasmin inhibitor complex which subsequently disappeared from the circulation in a short time. A decrease of other major inhibitors, such as $\alpha_{2}$-macroglobulin and $\alpha_{1}$-antitrypsin, was not observed when the amount of urokinase added or infused was relatively small, and conversion of plasminogen to plasmin was not extensive. The formation of plasmin$\alpha_{2}$-macroglobulin complex was observed only when plasma plasminogen was activated with a larger amount of urokinase, and after most of the $\alpha_{2}$-plasmin inhibitor was consumed by forming complexes with plasmin. The formation of plasmin- $\alpha_{1}$-antitrypsin complex was not observed even in the highly activated plasma unless exogenous plasmin was added to the plasma. $\alpha_{2}$-Plasmin inhibitor was the only inhibitor of which the concentration in plasma was significantly decreased in patients with disseminated intravascular coagulation and fibrinolysis among the major plasmin inhibitors in plasma. The most reactive inhibitor for regulating plasma fibrinolysis very likely is $\alpha_{2}$-plasmin inhibitor.

\section{INTRODUCTION}

A plasma fraction is known which inhibits plasminogen activator-induced clot lysis efficiently but pos-

Part of this data was presented at the International Society of Hematology Meeting, 8 September 1976. The research was carried out according to the provisions of the Declaration of Helsinki, and informed consent was obtained from each one of the patients.

Received for publication 23 September 1976 and in revised form 1 April 1977. sesses only a small part of the whole capacity of plasma to neutralize plasmin activity $(1,2)$. This fraction is called antiactivator, since it was found to be different from the major known plasmin inhibitors such as $\alpha_{2}$-macroglobulin $\left(\alpha_{2}-\mathrm{M}\right)^{1}$ and $\alpha_{1}$-antitrypsin $\left(\alpha_{1}-\mathrm{AT}\right)$, both which strongly inhibit plasmin on incubation but exert little effect on activator-induced clot lysis $(1,3)$. This antiactivator protein was purified, and its properties were investigated (4). The antiactivator was ultimately found to be primarily a plasmin inhibitor belonging to $\alpha_{2}$-globulin, and the term. $\alpha_{2}$-plasmin inhibitor $\left(\alpha_{2}-\mathrm{PI}\right)$ or $\alpha_{2}$-proteinase inhibitor is considered to be appropriate. $\alpha_{2}$-PI was shown to be different from $\alpha_{2}-\mathrm{M}, \mathrm{C} \overline{1}$ inactivator, inter- $\alpha$-trypsin inhibitor, $\alpha_{1}$-antichymotrypsin, $\alpha_{1}-\mathrm{AT}$, and antithrombin III (4). $\alpha_{2}$-PI inhibits plasmin almost instantaneously, and the inhibition of plasminogen activation by the inhibitor was found to be mainly due to the very rapid inactivation of plasmin formed (4). In this paper, we consider that this unique biological property of $\alpha_{2}$-PI has an important role in regulating fibrinolysis in vivo.

\section{METHODS}

Plasma. Human blood was collected from antecubital veins into a 0.1 -vol of $3.8 \%$ trisodium citrate and was centrifuged at $2,000 \mathrm{~g}$ at tip for $20 \mathrm{~min}$ to prepare plateletpoor plasma.

Preparation of purified plasminogen and plasmin. Plasminogen was prepared from human fresh plasma according to the method of Brockway and Castellino (5). Plasminogen fraction 2 , which was eluted after fraction 1 , was used for all the studies. Plasmin was prepared by activating plasminogen with urokinase-coupled Sepharose (Pharmacia Fine Chemicals, Div. of Pharmacia, Inc., Piscataway, N.J.) according to the method previously described (4). Activity of plasminogen and plasmin was assayed according to the caseinolytic method of Robbins and Summaria (6). Protein concentra-

${ }^{1}$ Abbreviations used in this paper: $\alpha_{2}-\mathrm{M}, \alpha_{2}$-macroglobulin; $\alpha_{2}$-PI, $\alpha_{2}$-plasmin inhibitor; $\alpha_{1}-\mathrm{AT}, \alpha_{1}$-antitrypsin; DIC, disseminated intravascular coagulation. 
tion of purified plasminogen was determined by measuring the absorbance of the plasminogen solution $(\mathrm{pH} 7.4)$ at 280 $\mathrm{nm}$ and by converting absorbance to protein concentration using $E_{1 \mathrm{~cm}}^{1 \%}=17.0$ for purified plasminogen (7).

Urokinase preparations. Urokinase preparations used for intravenous infusion were obtained from Green Cross Corp., Osaka and from Mochida Pharmaceutical Co., Tokyo. Activity was expressed by international units based on the standard preparations supplied by the World Health Organization. The unit is nearly equivalent to the Committee of Thrombolytic Agents unit.

Assay for plasma plasminogen and fibrinogen. Plasminogen in plasma was measured after destruction of antiplasmin by acidification (8). All plasmas to be assayed were first acidified by the addition of the equal volume of $0.166 \mathrm{~N} \mathrm{HCl}$, allowed to stand for $15 \mathrm{~min}$, reneutralized with $0.166 \mathrm{~N} \mathrm{NaOH}$, and then subjected to the caseinolytic method (6). The results were expressed in Remmert and Cohen casein units (9). The fibrinogen content of plasma was assayed by the method of Ratnoff and Menzie (10).

Immunochemical methods. Rabbit antisera against human $\alpha_{1}$-AT and $\alpha_{2}$-M were obtained from Behring-Werke AG, Marburg/Lahn, West Germany. Rabbit antiserum against human $\alpha_{2}$-PI was prepared by immunizing rabbits with a purified preparation of the inhibitor (4). About $1 \mathrm{mg}$ of protein in $1 \mathrm{ml}$ of $0.05 \mathrm{M}$ Tris- $\mathrm{HCl}, \mathrm{pH} 7.4$, containing $0.15 \mathrm{M} \mathrm{NaCl}$ was mixed completely with an equal volume of Freund's complete adjuvant and was injected in equally divided volumes intracutaneously into each footpad, shoulder, and thigh of a rabbit. $3 \mathrm{wk}$ later, the injection was repeated with $0.5 \mathrm{mg}$ protein. Immune sera were harvested $2-5 \mathrm{wk}$ after the second injection, and were absorbed with an $\alpha_{2}$-PIfree plasma fraction in step 4 of the purification procedures of the inhibitor described previously (4). The fraction had been passed through the plasminogen-coupled Sepharose column repeatedly to remove $\alpha_{2}$-PI completely. 1 vol of this plasma fraction, absorbancy of which was 17 at $280 \mathrm{~nm}$, was added to $40 \mathrm{vol}$ of antiserum, incubated at $37^{\circ} \mathrm{C}$ for 15 min, and stored at $4^{\circ} \mathrm{C}$ for $48 \mathrm{~h}$. The resulting precipitate was removed by centrifugation and discarded. The supernate was stored in a small aliquot with $0.1 \%$ of sodium azide as a preservative. Antiserum thus obtained was shown to be monospecific by double immunodiffusion and immunoelectrophoresis as previously described (4). The IgG fraction of antisera was obtained by DEAE-cellulose chromatography (11). Rabbit antiserum against human plasminogen was prepared by immunizing rabbits with a purified preparation of plasminogen. Immunization procedure was essentially the same as the one used for antiserum against $\alpha_{2}$-PI described above. About $10 \mathrm{mg}$ of protein was used for the first injection and $1.5 \mathrm{mg}$ for the second injection. Immune sera were absorbed with plasminogen-free human plasma which had passed through a column of lysine-Sepharose (4). 1 vol of fivefold-diluted plasminogen-free plasma was added to $9 \mathrm{vol}$ of antiserum, and the precipitate formed was removed.

The concentration of $\alpha_{2}-\mathrm{PI}$ in human plasma or serum was determined by the one-dimensional method of Laurell (12) using $1 \%$ antiserum in agarose $(0.8 \%$ in barbital buffer, $\mathrm{pH} 8.6$, ionic strength 0.05). $10 \mu$ l of antigen solution (purified inhibitor, plasma, or serum) was applied to the electrophoresis which was run with a constant current of $1 \mathrm{~mA} / \mathrm{cm}$ width for $7 \mathrm{~h}$. Dilutions of known amounts of the purified inhibitor were made with Tris-buffered saine (Tris $0.05 \mathrm{M}$, $\mathrm{NaCl} 0.15 \mathrm{M}, \mathrm{pH} 7.4$ ) containing $3 \% \mathrm{wt} / \mathrm{vol}$ bovine serum albumin and used for calibration. There was a linear relationship between peak heights and amounts of antigen applied (Fig. 1). The purified inhibitor used for calibration was the one which had the highest specific activity, 1,933
$U / \mathrm{ml}$ per $A_{280}(4)$, in a series of preparations and appeared as a single band on sodium dodecyl sulfate polyacrylamide gel electrophoresis. The protein concentrations of the purified inhibitor were determined by measuring the absorbance of the inhibitor solution ( $\mathrm{pH} 7.4$ ) at $280 \mathrm{~nm}$ and converting absorbance to protein concentration using $\mathrm{E}_{1}^{1 \% \mathrm{~cm}}=7.03$ for pure inhibitor (4). The extinction coefficient, $\mathrm{E}_{1}^{1 \%} \mathrm{~cm}$, was derived from the measurement of absorbance of the solution of known weight of the purified inhibitor, which had been extensively dialyzed to remove salts, lyophilized, and then dried in a vacuum at $110^{\circ} \mathrm{C}$ over $\mathrm{P}_{2} \mathrm{O}_{5}$ for 4 days.

The concentrations of $\alpha_{2}-\mathrm{M}$ and $\alpha_{1}-\mathrm{AT}$ in human plasma or serum were determined by the single radial immunodiffusion technique using partigen plates (Behring-Werke AG).

Antigen-antibody-crossed electrophoresis was performed essentially according to Laurell (13). $30 \mu \mathrm{l}$ of antigen solution was placed in a transverse slit $(1.5 \times 10 \mathrm{~mm})$ in the agarose layer $(0.8 \%$ agarose in barbital buffer, $\mathrm{pH} 8.6$, ionic strength 0.05 , and $1.8 \mathrm{~mm}$ thickness) on a glass slide $(2.5 \times 7.5 \mathrm{~cm})$. The electrophoresis was performed for about $2 \frac{1}{2} \mathrm{~h}$ with a constant current of $2 \mathrm{~mA} / \mathrm{cm}$ width. Afterwards the gel slip was transferred to a second glass plate $(5 \times 7.5 \mathrm{~cm})$. The remainder of the second plate was then covered with a layer of agarose containing $1 \%$ antiserum against $\alpha_{2}$-PI, $0.4 \%$ antiserum against plasminogen, or $2 \%$ antiserum against $\alpha_{1}-\mathrm{AT}$, separately. The second electrophoresis was performed by applying the electric current $(1 \mathrm{~mA}$ $\mathrm{cm}$ width) at an angle of $90^{\circ}$ to the direction of the first electrophoretic separation. The time of the second run was $10 \mathrm{~h}$. The buffer used for preparation of agarose gel and electrophoretic run was barbital buffer $(\mathrm{pH} 8.6$, ionic strength $0.05)$. The plates were washed with saline to remove nonprecipitated protein and dried. The immune precipitates were then stained with amido black.

' $\alpha_{2}-M$ ' antiplasmin activity. Antiplasmin activity of plasma was estimated by the modified method of the fibrinolytic assay described previously (1). $0.1 \mathrm{ml}$ of $30 \mu \mathrm{g} / \mathrm{ml}(0.52$ casein $\mathrm{U} / \mathrm{ml}$ ) plasmin in $25 \%$ glycerol was mixed and incubated at $37^{\circ} \mathrm{C}$ for $30 \mathrm{~min}$ with $0.1 \mathrm{ml}$ of the test plasma which had been diluted 20 -fold with barbital-buffered saline (5.2 mM barbital $0.14 \mathrm{M} \mathrm{NaCl}, \mathrm{pH} 7.4$ ). The mixture was then transferred to an ice-water bath, diluted with $0.6 \mathrm{ml}$ of cold barbital-buffered saline, and left for $3 \mathrm{~min}$. Subsequently, $0.1 \mathrm{ml}$ of fibrinogen solution followed by $0.1 \mathrm{ml}$ of

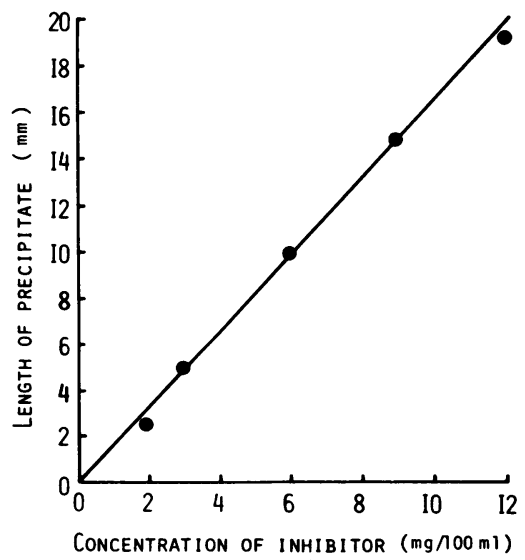

FIGURE 1 A reference curve for measuring the concentration of $\alpha_{2}$-PI by the one-dimensional method of Laurell (12). A linear relationship between concentration of purified $\alpha_{2}$-PI and length of precipitate (peak heights) was obtained. For details see the text. 
$20 \mathrm{U} / \mathrm{ml}$ bovine thrombin (Parke, Davis \& Company, Detroit, Mich.) was added, and the solution was transferred to a $37^{\circ} \mathrm{C}$ water bath, and the clot lysis time was recorded. Fibrinogen solution used was 2\% Cohn's fraction I of human plasma (Green Cross Corp., Osaka) which had been treated with lysine-Sepharose to remove plasminogen (14) and contained $1.6 \mathrm{~g} / 100 \mathrm{ml}$ of fibrinogen. The control was run by replacing the test plasma with buffered saline. The difference between the control measurement and the test run, expressed in fibrinolytic plasmin units as defined previously (1), divided by the volume $(0.1 \mathrm{ml})$ of the test sample, multiplied by the dilution factor 20 represents the antiplasmin units per milliliter. The determinations of the activity of plasma samples from 12 healthy adults revealed that the mean $\pm 2 \mathrm{SD}$ of normal values are $83 \pm 42 \mathrm{U} / \mathrm{ml}$. The antiplasmin activity measured by this method is referred to as $\alpha_{2}-\mathbf{M}$ antiplasmin activity, since the method measures mainly the antiplasmin activity of $\alpha_{2}-\mathrm{M}$ and is insensitive to the change of $\alpha_{2}-\mathrm{PI}$ activity $(1-3)$. Insensitivity of the method to the change of $\alpha_{2}$-PI may be explained by the fact that the method measures nearly total capacity of antiplasmin activity of whole plasma (1), and $\alpha_{2}$-PI contributes only $2.5 \%$ on average of the total antiplasmin activity (see Discussion).

Assay of $\alpha_{2}-P I$ activity. Activity of $\alpha_{2}$-PI in plasma or serum was assayed by the method based on the inhibitory activity of plasma or serum to activator-induced clot lysis $(1,2)$. Activator-induced clot lysis is principally inhibited by $\alpha_{2}$-PI but also by $\alpha_{2}-\mathrm{M}$ to a small degree (2). When plasminogen-free plasma prepared by lysine-Sepharose (4) was chromatographed on Sephadex G-200 (Pharmacia Fine Chemicals, Div. of Pharmacia, Inc.) as described previously (2), and each fraction of the effluent was analyzed for inhibitory activity to urokinase-induced clot lysis (2), the $\alpha_{2}-\mathrm{M}$ fraction which emerged in the first protein peak accounted for approximately $10-20 \%$ of the total activity of plasma depending on $\alpha_{2}-\mathbf{M}$ concentration in each plasma sample used. The inhibitory activity exerted by the $\alpha_{2}-\mathrm{M}$ fraction was diminished to approximately half by freezing and thawing the fraction, whereas inhibitory activity of $\alpha_{2}$-PI fraction which emerged later in the chromatography was not affected by a freezing-thawing procedure. This was also shown by the study using purified $\alpha_{2}-\mathrm{M}$ (15) and purified $\alpha_{2}$-PI. Inhibitor activity of $8 \mathrm{mg} / \mathrm{ml} \alpha_{2}-\mathrm{M}$ was $120 \mathrm{U} / \mathrm{ml}$ when assayed by the present method for $\alpha_{2}$-PI activity. The activity was diminished to $55 \mathrm{U} / \mathrm{ml}$ by freezing and thawing the same sample of $\alpha_{2}-\mathrm{M}$. However, a freezing-thawing procedure did not affect appreciably the inhibitor activity of purified $\alpha_{2}$-PI. Therefore, freezing and thawing the test sample before the assay decreases the activity by approximately $5-10 \%$ and makes the assay method more specific to $\alpha_{2}$-PI. The decrease of inhibitory activity of $\alpha_{2}-M$ to proteolytic enzymes (trypsin and chymotrypsin) by freezing and thawing procedures has been reported also by others (16). Since the presence of plasminogen in the test sample influences the assay method and gives erroneously lower values of inhibitor activity, plasminogen in the test sample was removed before the assay by lysine-Sepharose. $1 \mathrm{ml}$ of the test plasma or serum, once frozen and thawed, was applied on a column of lysineSepharose $(1 \mathrm{ml})$ equilibrated with barbital-buffered saline. The plasma was allowed to go into the column slowly and was followed with barbital-buffered saline. The first $5 \mathrm{ml}$ of the effluent, which contained more than $95 \%$ of the protein applied, was collected. This fivefold-diluted sample was used for the assay. An aliquot of the sample was diluted in the test tube $(10 \times 75 \mathrm{~mm})$ to $0.7 \mathrm{ml}$ with cold barbitalbuffered saline and was mixed with $0.1 \mathrm{ml}$ of $2 \%$ Cohn's fraction I of human plasma which contained $1.6 \mathrm{~g} / 100 \mathrm{ml}$ of fibrinogen and 1.2 casein $\mathrm{U} / \mathrm{ml}$ of plasminogen. The mixture was cooled in an ice-water bath. To this mixture were added $0.1 \mathrm{ml}$ of $600 \mathrm{CTA} \mathrm{U} / \mathrm{ml}$ urokinase (Mochida Pharmaceutical Co., Tokyo), and $0.1 \mathrm{ml}$ of $20 \mathrm{U} / \mathrm{ml}$ bovine thrombin to make a final clot of $1 \mathrm{ml}$. The tube was quickly shaken to mix the reagents well and placed in a $37^{\circ} \mathrm{C}$ water bath. A stopwatch was started at the time of addition of thrombin. Soon there formed a clot in which many small air bubbles were formed and trapped. The clot lysis was made noticeable by the sudden rise of the air bubbles to the upper surfaces. In another set of experiments, similar clot lysis tests without test sample were performed with various concentrations of urokinase. A standard curve was constructed by plotting on double-logarithmic paper the clot lysis time obtained by various concentrations of urokinase against units of urokinase in a $1-\mathrm{ml}$ clot. A straight line resulted over the range of 6-60 U urokinase/ml clot. Using this standard curve, clot lysis time obtained with a sample containing the inhibitor was converted to a value of urokinase activity. There was an inverse relationship between the amount of the inhibitor present and resulting residual urokinase activity, which is linear in the region from 60 urokinase $U$ (control with urokinase and no inhibitor) to $20 \mathrm{U} / \mathrm{ml}$ clot (urokinase plus various amounts of inhibitor). The inhibitor units per milliliter plasma or serum were calculated as the difference between the measurement of urokinase activity in the presence and in the absence of the test sample, expressed as units per milliliter clot divided by the volume (milliliters) of the test sample introduced into the assay system and multiplied by 5 (the dilution factor derived from the initial treatment of plasma or serum with lysine-Sepharose). The mean \pm SD of the activities of $\alpha_{2}$-PI in plasma from 29 healthy Japanese adults measured by this method were $1,224 \pm 374 \mathrm{U} / \mathrm{ml}$.

Specificity of the clot lysis method for $\alpha_{2}-P I$. The IgG fraction of rabbit antiserum to $\alpha_{2}$-PI or $\alpha_{2}-\mathrm{M}$ was added to lysine-Sepharose-treated and frozen-thawed plasma, incubated at $37^{\circ} \mathrm{C}$ for $1 \mathrm{~h}$ and further at $4^{\circ} \mathrm{C}$ for $24 \mathrm{~h}$. The resulting precipitates were removed by centrifugation. The residual inhibitor activity in the supernate was measured by the clot lysis method. 2, 1, 0.5, and $0.25 \mathrm{mg}$ of IgG fraction of anti- $\alpha_{2}-\mathrm{PI}$ antiserum neutralized $95,90,82$, and $70 \%$ of the inhibitor activity of $1 \mathrm{ml}$ plasma, respectively. The similar amounts of IgG fraction of anti- $\alpha_{2}-\mathrm{M}$ antiserum did not appreciably affect the inhibitor activity. This indicates that the assay method is specific to some extent for $\alpha_{2}$-PI, but the effect of any other proteinase inhibitor in plasma on the assay can not be excluded. Thrombin preparation used in the assay was crude material and might have been loaded with nonthrombin biologic activities. However, when purified thrombin prepared by the method of Lundblad (17) was used instead of crude thrombin, it gave the same results as those obtained with crude thrombin, suggesting that any contaminant in the crude thrombin preparation did not affect the assay.

Radioiodination of plasminogen. Plasminogen was radioiodinated by modification of the method of Greenwood et al. (18). To $13 \mathrm{mg}$ of plasminogen in $6 \mathrm{ml}$ of Tris-saline $(0.05$ $\mathrm{M}$ Tris- $\mathrm{HCl}, \mathrm{pH} 7.4,0.15 \mathrm{M} \mathrm{NaCl}$ ) were added $0.15 \mathrm{mg}$ of $\mathrm{NaI}$ in $0.15 \mathrm{ml}$ of $0.05 \mathrm{M}$ phosphate buffer $(\mathrm{pH} 7.4$ ) and $80 \mu \mathrm{Ci}$ of ${ }^{125} \mathrm{I}-\mathrm{Na}$ solution (The Radiochemical Centre, Amersham, England) while stirring in an ice water bath. Immediately thereafter, $0.4 \mathrm{mg}$ of chloramine-T (Tokyo Kasei Co., Ltd., Tokyo) in $0.1 \mathrm{ml}$ of phosphate buffer was added, and the mixture was stirred for $1 \mathrm{~min}$. Then $0.1 \mathrm{ml}$ of $\mathrm{Na}_{2} \mathrm{~S}_{2} \mathrm{O}_{2}$ solution ( $4 \mathrm{mg} / \mathrm{ml}$ phosphate buffer) was added to stop the reaction. Separation of ${ }^{125}$ I-plasminogen from the reaction mixture was carried out by gel filtration through a column of Sephadex G-50. Elution was initially carried out with 0.6 $\mathrm{ml}$ of the mixture of $\mathrm{NaI}(0.4 \mathrm{mg})$ and $\mathrm{KI}(2 \mathrm{mg})$, followed by 
Tris-saline. Specific activity of plasminogen before and after radioiodination were 23.1 and $20.2 \mathrm{U} / \mathrm{mg}$ protein, respectively.

Distribution of ${ }^{125}$ I-plasminogen or plasmin in urokinaseactivated plasma. $20 \mu \mathrm{l}$ of radioiodinated plasminogen $(0.91 \mathrm{mg} / \mathrm{ml})$ was added to $2 \mathrm{ml}$ plasma, yielding plasma containing $9 \mu \mathrm{g}$ radioiodinated plasminogen $/ \mathrm{ml}$. This plasma was activated with various amounts of urokinase and was subjected to electrophoresis in agarose in the same way as the first electrophoresis of antigen-antibody-crossed electrophoresis. Immediately after the completion of electrophoresis, the gel was cut transversely into 3-mm slices. Each slice was put into a counting vial, and radioactivity was counted by Auto Well Gamma System, Aloka JDC-752 (Aloka Co., Tokyo).

Statistical analysis. Statistical analysis was performed by Student's $t$ analysis for paired or unpaired samples where applicable. For unpaired samples, Snedecor and Cochran's modification was applied (19). A $P$ value $>0.05$ was considered to represent a statistically nonsignificant change. The two-tailed test was used unless otherwise indicated.

Patients. Effects of intravenous infusion of urokinase on plasma plasmin inhibitors were studied on seven patients who received urokinase therapy within $72 \mathrm{~h}$ after an attack of cerebral infarction. $240,000 \mathrm{U}$ of urokinase was administered to each patient except for one patient who received $120,000 \mathrm{U}$.

Patients having disseminated intravascular coagulation (DIC) with fibrinolysis were studied for the concentrations of plasmin inhibitors. The diagnosis of DIC was based on clinical observations as well as laboratory findings such as increased fibrin/fibrinogen degradation products $(16-640 \mu \mathrm{g} /$ $\mathrm{ml}$, normal $<4 \mu \mathrm{g} / \mathrm{ml}$ [20]), decreased plasma antithrombin III activity $(10-80 \%$ of normal standard, normal range $90-$ $110 \%$ [2!] ), prolonged prothrombin time (>15 s, normal 12$13 \mathrm{~s}$ [22]), decreased plasminogen $(0.2-1.4$ casein $\mathrm{U} / \mathrm{ml}$, normal range 1.4-2.0 casein $\mathrm{U} / \mathrm{ml}$ ), decreased fibrinogen (20-200 mg/100 ml, normal range $150-400 \mathrm{mg} / 100 \mathrm{ml}$ ), and decreased platelet count $(<150,000 / \mu 1$, normal range $150,000-$ $400,000 / \mu \mathrm{l}$ ) measured by Coulter counter (Coulter Electronics Inc., Hialeah, Fla.). These values were obtained by the repeated assays during the course of the diseases rather than by a determination on a single occasion. The gradual or sudden decline of platelet count, fibrinogen, plasminogen, and antithrombin III activity, together with further prolongation of prothrombin time and persistent presence or a steady increase of fibrin/fibrinogen degradation products, was most suggestive of DIC. Underlying diseases were carcinoma, acute leukemia, and septicemia.

\section{RESULTS}

Development of the complexes of plasmin and inhibitors in urokinase-activated plasma in vitro. Plasma was incubated with various amounts of urokinase, and subsequently subjected to antigen-antibody-crossed electrophoresis. Control plasma without addition of urokinase contained $\alpha_{2}$-PI as a single component (Fig. 2A). When plasma was activated with urokinase, there appeared a new component which possessed the antigenicity of $\alpha_{2}$-PI with a slower mobility in the electrophoretic field as indicated by arrow 1 (Fig. 2A). The new component became more prominent, and the $\alpha_{2}$-PI component itself was diminished when the amount of urokinase was increased, as seen in the bottom figure of Fig. 2A. The new component disappeared after the plasma was absorbed with antiplasminogen antiserum, indicating that it is a complex between $\alpha_{2}$-PI and plasmin generated by urokinase. When antigen-antibody-crossed electrophoresis was carried out using antiplasminogen antiserum, the appearance of another new component with a faster mobility was found in the plasma activated with high concentrations of urokinase $(>100$ $\mathrm{U} / \mathrm{ml}$ ) as indicated by arrow 2 in Fig. 2B. This component became less prominent when the plasma was absorbed before electrophoresis with anti- $\alpha_{2}-\mathrm{M}$ antiserum, indicating that the component is the complex of $\alpha_{2}-\mathrm{M}$ and plasmin. It is noteworthy that the complex of $\alpha_{2}-\mathrm{M}$ and plasmin did not develop when the concentration of urokinase was as low as $25 \mathrm{U} / \mathrm{ml}$ (Fig. 2B), whereas the formation of the complex of $\alpha_{2}$-PI and plasmin was observed (Fig. 2A).

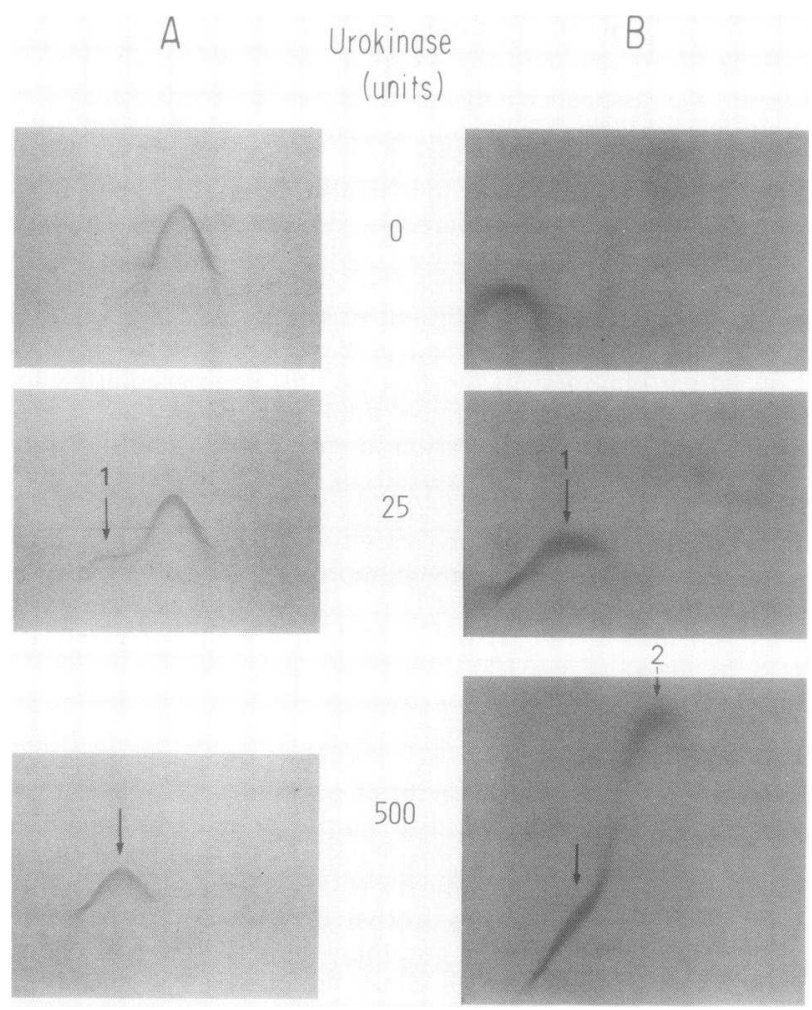

FIGURE 2 Formation of the complex of the plasma inhibitors and plasmin in plasma activated with urokinase in vitro, demonstrated by antigen-antibody-crossed electrophoresis. To each $1 \mathrm{ml}$ of plasma was added 2.5 and 50 $\mu$ l of urokinase solution $(10,000 \mathrm{U} / \mathrm{ml})$ separately, and the mixtures were incubated at $37^{\circ} \mathrm{C}$ for $2 \mathrm{~h}$ and further at room temperature for an additional $12 \mathrm{~h}$. They were subsequently subjected to antigen-antibody crossed electrophoresis using antisera against $\alpha_{2}$-PI (A) or plasminogen (B). The direction of the first electrophoresis was from the left to the right. The amounts (units) of urokinase added to $1 \mathrm{ml}$ plasma are indicated between the panels. Arrows indicate the complex of plasmin and inhibitors. Arrow 1, the complex of $\alpha_{2}$-PI and plasmin. Arrow 2, the complex of $\alpha_{2}-\mathrm{M}$ and plasmin. 
When these urokinase-activated plasma samples were analyzed by the crossed electrophoresis using antiserum against $\alpha_{1}$-AT, no formation of the complex of $\alpha_{1}$-AT and plasmin was observed, even in plasma activated with high concentrations of urokinase, such as $500 \mathrm{U} / \mathrm{ml}$ plasma. In these plasma samples, nearly all plasminogen was converted to plasmin, and most of the $\alpha_{2}$-PI formed complexes with plasmin (Fig. 2). The formation of the complex of $\alpha_{1}$-AT and plasmin was observed only after the addition of exogenous plasmin to this highly activated plasma.

Plasma containing radioiodinated plasminogen was activated with urokinase, and the distribution of radioactivity in plasma fractions was analyzed by electrophoresis. The results are shown in Fig. 3. When plasma was activated with $25 \mathrm{U}$ of urokinase $/ \mathrm{ml}$ plasma, the peak of radioactivity shifted to the location (slice 5 ) corresponding to the peak of $\alpha_{2}$-PI-plasmin complex indicated by arrow 1 in Fig. 2A (Fig. 3A). The peak of $\alpha_{2}$-PI-plasmin complex became prominent with concurrent decrease of the original plasminogen peak (slice 3) when amounts of urokinase used were increased (Fig. 3B). With increasing urokinase, there developed another new peak of radioactivity (slice 9) which corresponds to the location of the peak indi-
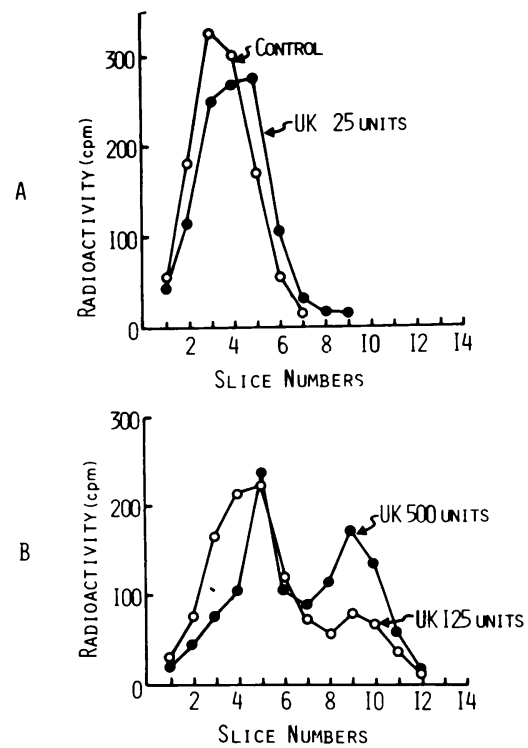

FIGURE 3 Distribution of radioactivity in plasma fractions after activation of plasma containing radioiodinated plasminogen with urokinase. To each $1 \mathrm{ml}$ of plasma was added $2.5,12.5$, and $50 \mu \mathrm{l}$ of urokinase solution $(10,000 \mathrm{U} / \mathrm{ml})$ separately, and the mixtures were incubated at $37^{\circ} \mathrm{C}$ for $2 \mathrm{~h}$ and further at room temperature for additional $12 \mathrm{~h}$. They were subsequently subjected to electrophoresis in agarose, and the distribution of radioactivity was analyzed. The amounts of urokinase added to $1 \mathrm{ml}$ plasma are indicated on each figure. Control was run without addition of urokinase. Slices of agarose plate are numbered from the origins where the samples were applied. Details of the method are described in the text. UK, urokinase.

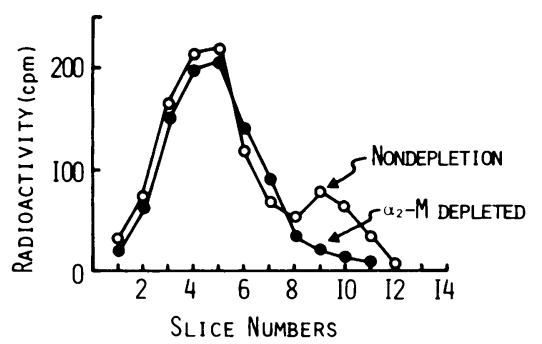

Figure 4 Depletion of plasmin $-\alpha_{2}-\mathbf{M}$ complex by antiserum against $\alpha_{2}-\mathrm{M} .0 .1 \mathrm{ml}$ of antiserum was added to $1 \mathrm{ml}$ plasma which contained radioiodinated plasminogen and had been incubated with $125 \mathrm{U} / \mathrm{ml}$ urokinase as in Fig. 3. The mixture was then incubated at $37^{\circ} \mathrm{C}$ for $30 \mathrm{~min}$ and further at $4^{\circ} \mathrm{C}$ for additional $12 \mathrm{~h}$. The resulting precipitates were removed by centrifugation and the supernate was subjected to electrophoresis. The condition of the electrophoresis and the subsequent treatment were the same as in Fig. 3. The control (nondepletion) was run by replacing rabbit antiserum with unimmunized rabbit serum.

cated by arrow 2 in Fig. 2B (Fig. 3B). This new peak is most likely attributable to the formation of the $\alpha_{2}-\mathrm{M}$-plasmin complex, in that the peak was destroyed by the treatment of the plasma with anti- $\alpha_{2}-\mathrm{M}$ antiserum before electrophoresis (Fig. 4).

Development of the complexes of plasmin and inhibitors in plasma of patients receiving urokinase intravenously. For therapeutic purposes 240,000 or $120,000 \mathrm{U}$ of urokinase together with $5,000 \mathrm{U}$ of heparin was infused intravenously for $2 \mathrm{~h}$ to seven different patients with cerebral infarction. Immediately before the infusion, and at $0,3,6$ and $18 \mathrm{~h}$ after the termination of the infusion, blood samples were withdrawn from the patients and subjected to analyses by antigen-antibody-crossed electrophoresis (Fig. 5). The complex of $\alpha_{2}$-PI and plasmin was observed prominently in the samples withdrawn immediately after the infusion (Fig. 5). The complex became less prominent at $3 \mathrm{~h}$, and no complex was found at $6 \mathrm{~h}$ after the infusion (Fig. 5). The antigen concentration, as well as the activity of $\alpha_{2}$-PI, decreased concurrently with the appearance of the complex of $\alpha_{2}$-PI and plasmin. The decrease of activity was more remarkable than that of antigen concentration at the time immediately after the infusion (Fig. 5). The complex of plasmin and $\alpha_{2}-\mathrm{M}$ or $\alpha_{1}-\mathrm{AT}$ as described in in vitro studies mentioned above was not found at any time.

Decrease of $\alpha_{2}$-PI after the intravenous infusion of urokinase. To continue our studies in these patients, concentrations (antigen) of the inhibitors, $\alpha_{2}$-PI, $\alpha_{2}-\mathrm{M}$, and $\alpha_{1}-\mathrm{AT}$, in plasma were measured immunochemically before and after the intravenous infusion $(2 \mathrm{~h})$ of $240,000 \mathrm{U}$ of urokinase together with $5,000 \mathrm{U}$ of heparin. Inhibitory activity of $\alpha_{2}$-PI, $\alpha_{2}-\mathrm{M}$ antiplasmin activity, plasminogen, and fibrinogen were also assayed. The concentrations and the activity of 


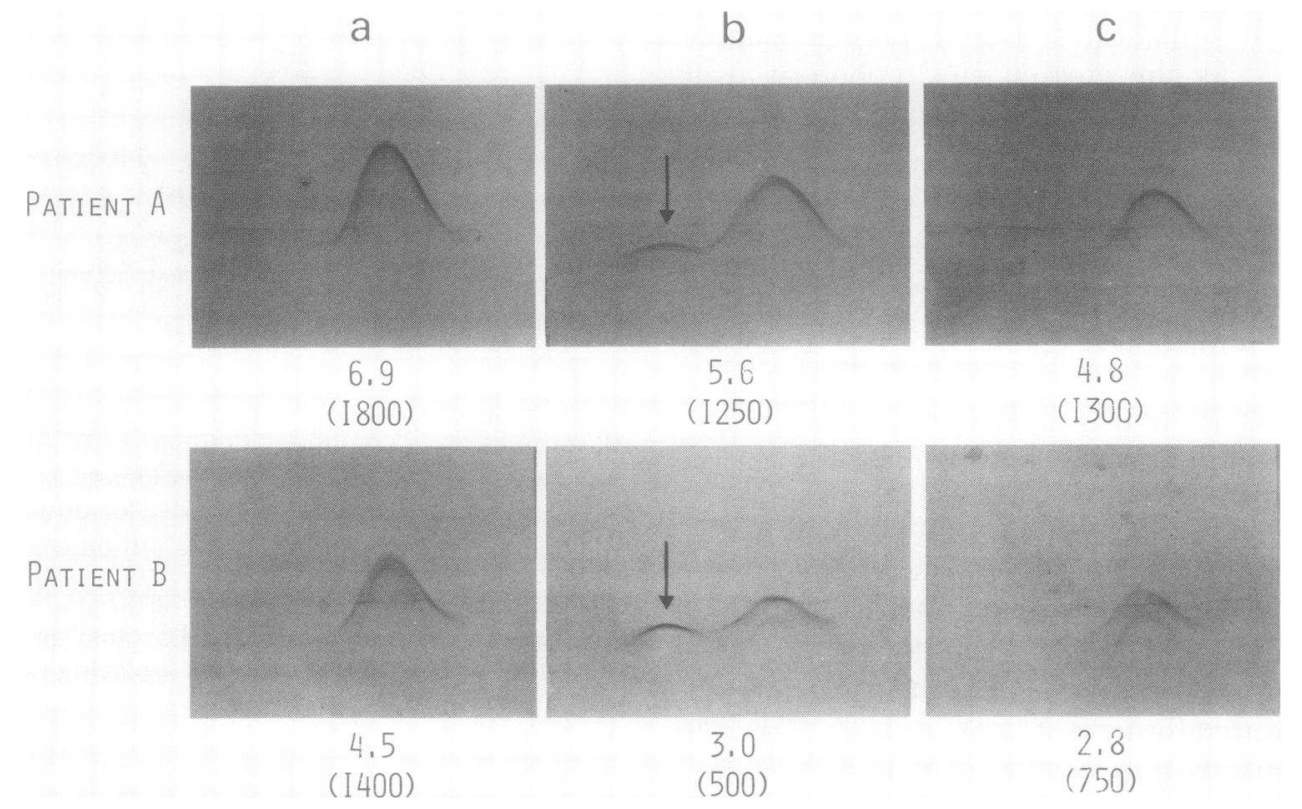

FIgURE 5 Formation and disappearance of the complex of $\alpha_{2}$-PI and plasmin in plasma of the patients under urokinase treatment, demonstrated by antigen-antibody-crossed electrophoresis using antiserum against $\alpha_{2}$-PI. Plasma samples were withdrawn from the patients before $(a)$, immediately after $(b)$, and $6 \mathrm{~h}$ after $(c)$ the infusion of urokinase. Patients A and B received 120,000 and $240,000 \mathrm{U}$ of urokinase, respectively. Arrows indicate the complex of $\alpha_{2}$-PI and plasmin. The concentration ( $\mathrm{mg}$ antigen $/ 100 \mathrm{ml}$ ) and the activity $\left(\mathrm{U} / \mathrm{ml}\right.$ shown in parentheses) of $\alpha_{2}$-PI are indicated under each figure.

$\alpha_{2}$-PI were significantly decreased by the infusion of urokinase and had not yet returned to the original values when examined at $18 \mathrm{~h}$ after the termination of infusion (Tables I and II). On the contrary, the concentrations of $\alpha_{2}$-M and $\alpha_{1}$-AT were not changed significantly by the infusion. Some significant increase of $\alpha_{2}-\mathrm{M}$ antiplasmin activity was noticed at the time immediately after the infusion (Table II). Plasminogen

\section{TABLE I}

Changes in the Concentrations of Inhibitors in Plasma after a 2-h Urokinase Infusion

\begin{tabular}{lccc}
\hline & \multicolumn{3}{c}{ Time after the start of infusion, $h$} \\
\cline { 2 - 4 } Inhibitors & 0 & 2 & 20 \\
\hline & & $m g / 100 m l$ & \\
$\alpha_{2}$-PI & $4.78 \pm 1.27^{*}$ & $3.42 \pm 0.52$ & $3.02 \pm 0.29$ \\
& & $P<0.02 \ddagger$ & $P<0.02$ \\
$\alpha_{2}-\mathrm{M}$ & $191 \pm 22$ & $191 \pm 19$ & $198 \pm 26$ \\
& & $\mathrm{NS}$ & $\mathrm{NS}$ \\
$\alpha_{1}-\mathrm{AT}$ & $244 \pm 40$ & $248 \pm 41$ & $261 \pm 24$ \\
& & $\mathrm{NS}$ & $\mathrm{NS}$ \\
\hline
\end{tabular}

* Mean \pm SD $(n .=6)$.

$\$ P$ values refer to the difference in concentrations in samples at 2 or $20 \mathrm{~h}$ from those in samples at 0 time. decreased significantly after urokinase infusion, whereas fibrinogen remained unchanged (Table III).

Decrease of $\alpha_{2}$ PI in DIC with fibrinolysis. Concentrations of $\alpha_{2}-\mathrm{PI}, \alpha_{2}-\mathrm{M}$, and $\alpha_{1}-\mathrm{AT}$ in plasma were measured immunochemically in patients having DIC with fibrinolysis, and compared with normal values. The mean \pm 2 SD of the concentrations of $\alpha_{2}$-PI in plasma from 25 healthy Japanese adults were 5.98 $\pm 1.76 \mathrm{mg} / 100 \mathrm{ml}$. The reported values of the mean $\pm 2 \mathrm{SD}$ of concentrations of $\alpha_{2}$-M and $\alpha_{1}$-AT in plasma

TABLE II

Changes in Inhibitor Activities of Plasma after a 2-h Urokinase Infusion

\begin{tabular}{lccc}
\hline & \multicolumn{3}{c}{ Time after the start of infusion, $h$} \\
\cline { 2 - 4 } \multicolumn{1}{c}{ Inhibitors } & 0 & 2 & 20 \\
\hline & & $U / m l$ & \\
$\alpha_{2}$-PI & $1,461 \pm 298^{*}$ & $588 \pm 206$ & $911 \pm 244$ \\
& & $P<0.001 \ddagger$ & $P<0.005$ \\
$\alpha_{2}-\mathrm{M}$ & $103 \pm 22$ & $136 \pm 18$ & $95 \pm 22$ \\
antiplasmins & & $P<0.05$ & $\mathrm{NS}$ \\
\hline
\end{tabular}

* Mean \pm SD $\left(\alpha_{2}-\mathrm{PI}, n=6 ; \alpha_{2}-\mathrm{M}, n=5\right)$.

$\$ P$ values refer to the difference in activities in samples at 2 or $20 \mathrm{~h}$ from those in samples at 0 time. 
TABLE III

Changes in the Concentrations of Plasminogen and Fibrinogen in Plasma after a $2-h$ Urokinase Infusion

Time after the start of infusion, $h$

$\mathbf{0}$

2

20

\begin{tabular}{cccc}
\hline $\begin{array}{c}\text { Plasminogen, } \\
\text { casein U/ml }\end{array}$ & $1.41 \pm 0.26^{*}$ & $1.06 \pm 0.22$ & $1.05 \pm 0.3$ \\
& & $P<0.0005 \ddagger$ & $P<0.05$ \\
$\begin{array}{c}\text { Fibrinogen, } \\
m g / 100 \mathrm{ml}\end{array}$ & $394 \pm 123$ & $337 \pm 91$ & $346 \pm 86$ \\
& & $\mathrm{NS}$ & $\mathrm{NS}$ \\
\hline
\end{tabular}

* Mean $\pm \operatorname{SD}(n=5)$.

$\ddagger P$ values refer to the difference in concentrations in samples at 2 or $20 \mathrm{~h}$ from those in samples at 0 time. One-tailed test.

from 160 healthy Japanese adults measured by single radial immunodiffusion are $210 \pm 100$ and $200 \pm 100$ $\mathrm{mg} / 100 \mathrm{ml}$, respectively (23). The concentrations of $\alpha_{2}$-PI in most of the patients were found to be lower than the normal range, whereas values of $\alpha_{2}$-M were in the normal range except for one case, and those of $\alpha_{1}$-AT were higher in many cases than the normal range (Fig. 6). Many of the values of $\alpha_{2}-\mathrm{M}$, even though in the normal range, were well below the mean level of normals, thus implying that there had been some reduction in the level in those cases. No complex of plasmin with any one of the inhibitors was detected when these patients' plasmas were analyzed by antigen-antibody-crossed electrophoresis.
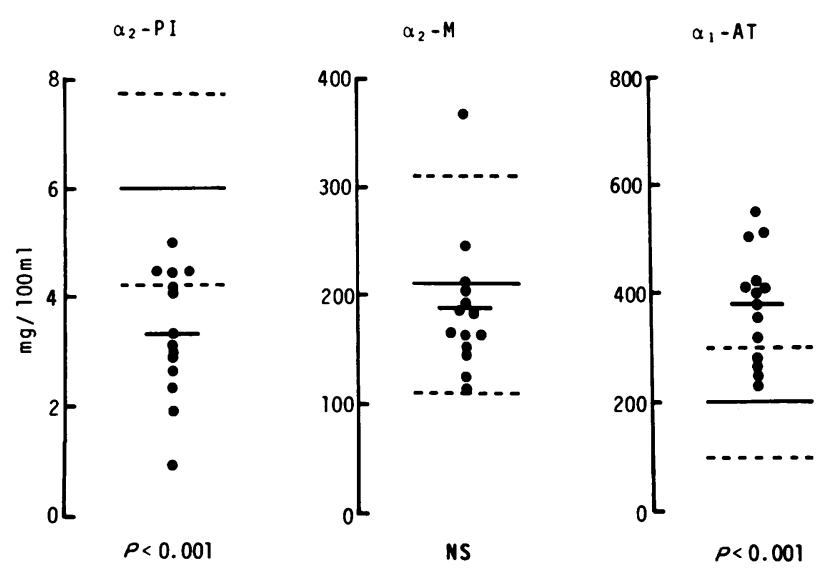

FIgURE 6 Concentrations of $\alpha_{2}-\mathrm{PI}, \alpha_{2}-\mathrm{M}$, and $\alpha_{1}$-AT in plasma of the patients with DIC, measured by the immunochemical method. The mean concentration of each inhibitor is indicated by a short horizontal line. The means \pm 2 SD of normal values for healthy adults are indicated by solid and interrupted horizontal lines, respectively. $P$ values refer to the difference in concentrations in DIC from those in normal.

\section{DISCUSSION}

The concentration of $\alpha_{2}$-PI in normal plasma was found to be approximately $5-7 \mathrm{mg} / 100 \mathrm{ml}$, which is calculated to be $\cong 0.7-1.0 \mu \mathrm{M}$ on the basis of mol wt 67,000 . The molar concentrations of $\alpha_{2}-\mathrm{M}$ (mol wt 820,000$)$ and $\alpha_{1}$-AT (mol wt 54,000) in normal plasma are estimated on the average at 2.4 and $37 \mu \mathrm{M}$, respectively, while their average concentrations are 210 and $200 \mathrm{mg} / 100$ $\mathrm{ml}$, respectively (23). Consequently, it may be concluded on the assumption of one-to-one molar reaction of inhibitor and enzyme that $\alpha_{2}$-PI contributes only $2.5 \%$ on average of the total capacity of antiplasmin activity of the whole plasma. However, $\alpha_{2}$-PI has the strongest affinity for plasmin among these inhibitors. It had been suggested that the strong affinity of $\alpha_{2}$-PI for plasmin plays an important role in the regulation of fibrinolysis. To test this possibility, the behavior of $\alpha_{2}$-PI in fibrinolytic states was explored in the present study.

When plasminogen in plasma was activated in vitro by a relatively low concentration of urokinase, there appeared readily a plasmin- $\alpha_{2}-P I$ complex. However, no complex of plasmin- $\alpha_{2}-\mathrm{M}$ or $\alpha_{1}-\mathrm{AT}$ was observed. The formation of the plasmin- $\alpha_{2}-\mathrm{M}$ complex was observed only when plasma was activated with a larger amount of urokinase and after most of the $\alpha_{2}$-PI was consumed by forming complexes with plasmin. The formation of plasmin- $\alpha_{1}-\mathrm{AT}$ complex was not observed even when all of the plasminogen in plasma was converted to plasmin unless exogenous plasmin was added.

When a relatively low dose of urokinase was infused intravenously to patients, the consistent findings were the decrease of the concentration and the activity of $\alpha_{2}$-PI and the concomitant formation of the plasmin$\alpha_{2}$-PI complex. The decrease of the activity of $\alpha_{2}$-PI was more remarkable than that of the concentration at the time of the existence of the complex in blood. This can be explained by the fact that the concentration measured by the immunochemical method includes the enzyme-inhibitor complex which has lost the activity.

In contrast to $\alpha_{2}-\mathrm{PI}$, concentrations of $\alpha_{2}-\mathrm{M}$ and $\alpha_{1}$-AT were not significantly changed, and no complex of plasmin- $\alpha_{2}-\mathrm{M}$ or $-\alpha_{1}-\mathrm{AT}$ was observed.

A significant increase of $\alpha_{2}-\mathrm{M}$ antiplasmin activity observed immediately after the infusion might be attributable to antiplasmin activity of heparin-antithrombin III (24), because there was no significant increase of $\alpha_{2}-\mathrm{M}$ antigen concentration throughout the study, and no significant increase of $\alpha_{2}-\mathrm{M}$ antiplasmin activity was observed $18 \mathrm{~h}$ after the termination of infusion when no residual effect of heparin was detected.

Arnesen and Fagerhol studied effects of urokinase in- 
fusion on $\alpha_{2}-\mathrm{M}, \alpha_{1}-\mathrm{AT}$, and antithrombin III in plasma (25). The doses of urokinase that they used were far greater than those used in the present study. They infused nearly twofold the amount of urokinase as compared to ours in $10 \mathrm{~min}$ as a loading dose and continued infusion of a maintenance dose for $18 \mathrm{~h}$. Their hourly maintenance dose is nearly equivalent to the total amount of urokinase infused into each patient in the present study. In spite of their large dose, the decrease of $\alpha_{2}$-M after completion of infusion was only $20 \%$ on average of the preinfusion values. There was no change of plasma antithrombin III level, and the concentration of $\alpha_{1}$-AT was even increased. Niléhn and Ganrot activated practically all plasminogen by infusing a large dose of streptokinase and observed the decrease of $\alpha_{2}-\mathrm{M}$ to $50 \%$ of the initial values (26). In the present study, the decrease of plasminogen level averaged $25 \%$ of the preinfusion values, and no decrease of $\alpha_{2}-\mathrm{M}$ was observed. These data, together with those obtained by others $(27,28)$, indicate that $\alpha_{2}-\mathrm{M}$ is one of the major antiplasmins which react with plasmin generated during fibrinolytic therapy. The present study provides, furthermore, information on a newly discovered inhibitor in addition to $\alpha_{2}$-M.

The present study suggests that $\alpha_{2}$-PI is the most reactive plasmin inhibitor in plasma, and whenever plasminogen activation takes place, $\alpha_{2}$-PI is the first inhibitor which reacts with plasmin formed. Only when the excess amount of plasmin is formed, and when most $\alpha_{2}$-PI has been consumed by forming complexes with plasmin, then $\alpha_{2}-\mathrm{M}$ will become the principal inhibitor to plasmin. This view is supported by the finding that, among the major plasmin inhibitors in plasma, $\alpha_{2}$-PI was the only inhibitor of which the concentration was significantly decreased in patients with DIC. However, no complex of plasmin- $\alpha_{2}$-PI was observed in plasma of these patients, at least by the method presently employed. This is explained by the rapid disappearance of plasmin- $\alpha_{2}$-PI complex from the circulating blood, which, in the present study, was indeed shown after the infusion of urokinase. The plasmin- $\alpha_{2}$-PI complex formed after intravenous infusion of $240,000 \mathrm{U}$ of urokinase disappeared from the circulating blood within $6 \mathrm{~h}$. The complex was probably removed by the clearance mechanism of the reticuloendothelial system in organs especially in the liver, since the complex is formed by a stable covalent bond (4), and its dissociation can not readily occur. $\alpha_{2}$-M might also have reacted with plasmin in these DIC patients, inasmuch as almost all values of $\alpha_{2}-\mathrm{M}$ were below the mean value although they were in the normal range. However, this possibility was not statistically proved in the present study $(P>0.1)$. The cause of the increase of $\alpha_{1}$-AT observed in these DIC patients was not known, but it is interesting to note that $\alpha_{1}$-AT concentration in plasma was steadily increasing during prolonged infusion of urokinase (25).

Because the molecular weight of the complex of $\alpha_{2}$-PI and the light chain of plasmin was previously reported as 84,000 (4) and the molecular weight of the heavy chain was nearly 67,000 (4), the molecular weight of plasmin- $\alpha_{2}$-PI complex must be close to 150,000 . The plasmin- $\alpha_{2}$-PI complex might be the same as the complex reported by Collen et al. (29). They reported that, during the activation of plasminogen in plasma with urokinase in vitro, there appeared the complex of plasmin and a hitherto unidentified antiplasmin. The molecular weight of this complex was estimated by gel filtration to be in the region of $130,000-170,000$, which is the same region of the estimate of molecular weight of plasmin- $\alpha_{2}$-PI complex. Müllertz (30) also reported that urokinaseactivated plasma contained, at a low concentration of urokinase, a component with plasmin + plasminogen antigenicity which was eluted with nearly $7 \mathrm{~S}$ protein from Sephadex G-200 and had $\beta$-mobility by gel electrophoresis. This component appears from its physical properties to be identical with plasmin- $\alpha_{2}$-PI complex.

In addition to these observations, plasma inhibitors of fibrinolysis which possess properties similar to those of $\alpha_{2}$-PI were recently described (31-35). The question as to whether or not $\alpha_{2}$-PI is identical with any one of these inhibitors needs further investigation, including elucidation of the physicochemical and immunochemical properties of each inhibitor.

Crossed immunoelectrophoresis of some plasma samples using anti- $\alpha_{2}$-PI antisera gave double immunoprecipitate lines as seen in patient B in Fig. 5 . Development of double immunoprecipitate lines might be due to the molecular heterogeneity of antigen as suggested by Laurell (36), and the antisera might contain antibodies against more than one of the determinants. Molecular heterogeneities of $\alpha_{2}-\mathrm{M}$ and $\alpha_{1}$-AT have already been revealed by crossed immunoelectrophoresis (37). Another possibility that the antiserum is not specific and reacts with two different molecules which possess the same electrophoretic mobility cannot be excluded, although immunoelectrophoresis and double immunodiffusion have not been able to demonstrate this possibility (4).

\section{ACKNOWLEDGMENTS}

The authors would like to thank Dr. M. Yoshida and Dr. A. Ueki of the Department of Neurology at the Jichi Medical School for their generous cooperation. Acknowledgment is also due to Dr. W. H. Seegers, Wayne State University, for his critical reading.

This work was supported by a grant from the Ministry of Education of the Government of Japan. 


\section{REFERENCES}

1. Aoki, N., and K. N. von Kaulla. 1971. Human serum plasminogen antiactivator: its distinction from antiplasmin. Am. J. Physiol. 220: 1137-1145.

2. Aoki, N., and T. Kawano. 1972. Inhibition of plasminogen activators by naturally occurring inhibitors in man. Am.J. Physiol. 223: 1334-1337.

3. Aoki, N., and M. Moroi. 1974. Distinction of serum inhibitor of activator-induced clot lysis from $\alpha_{1}$-antitrypsin. Proc. Soc. Exp. Biol. Med. 146: 567-570.

4. Moroi, M., and N. Aoki. 1976. Isolation and characterization of $\alpha_{2}$-plasmin inhibitor from human plasma. A novel proteinase inhibitor which inhibits activator-induced clot lysis. J. Biol. Chem. 251: 5956-5965.

5. Brockway, W. J., and F. J. Castellino. 1972. Measurement of the binding of antifibrinolytic amino acids to various plasminogens. Arch. Biochem. Biophys. 151: $194-199$.

6. Robbins, K. C., and L. Summaria. 1970. Human plasminogen and plasmin. Methods Enzymol. 19: 184-199.

7. Barlow, G. H., L. Summaria, and K. C. Robbins. 1969. Molecular weight studies on human plasminogen and plasmin at the microgram level. J. Biol. Chem. 244: $1138-1141$.

8. Alkjaersig, N., A. P. Fletcher, and S. Sherry. 1959. The mechanism of clot dissolution by plasmin. J. Clin. Invest. 38: 1086-1095.

9. Remmert, L. F., and P. P. Cohen. 1949. Partial purification and properties of a proteolytic enzyme of human serum. J. Biol. Chem. 181: 431-448.

10. Ratnoff, O. D., and C. Menzie. 1951. A new method for the determination of fibrinogen in small samples of plasma. J. Lab. Clin. Med. 37: 316-320.

11. Rowe, D. S., and J. L. Fahey. 1965. A new class of human immunoglobulins. II. Normal serum IgD. J. Exp. Med. 121: 185-199.

12. Laurell, C. B. 1966. Quantitative estimation of proteins by electrophoresis in agarose gel containing antibodies. Anal. Biochem. 15: 45-52.

13. Laurell, C. B. 1965. Antigen-antibody crossed electrophoresis. Anal. Biochem. 10: 358-361.

14. Matsuda, M., S. Iwanaga, and S. Nakamura. 1972. A simple, large scale method for preparation of plasminogen-free fibrinogen. Thromb. Res. 1: 619-630.

15. Iwamoto, M., and Y. Abiko. 1970. Plasminogen-plasmin system. Preparation of $\alpha_{2}$-macroglobulin antiplasmin from human plasma. Biochim. Biophys. Acta. 214: $402-410$.

16. Lebreton de Vonne, T., H. Mouray, G. Berthillier, and R. Got. 1972. Influence du vieillissement des $\alpha_{2}$-macroglobulines de lapin sur la formation du complexe $\alpha_{2}$ macroglobuline-enzymes. Biochim. Biophys. Acta. 257: 365-371.

17. Lundblad, R. L. 1971. A rapid method for the purification of bovine thrombin and the inhibition of the purified enzyme with phenylmethylsulfonyl fluoride. Biochemistry. 10: 2501-2506.

18. Greenwood, F. C., W. M. Hunter, and J. S. Glover 1963. The preparation of ${ }^{131}$ I-labelled human growth hormone of high specific radioactivity. Biochem. J. 89: 114- 123 .
19. Snedecor, G. W., and W. G. Cochran. 1967. Statistical Methods. Iowa State University Press, Ames, Iowa. 6th edition. 114-116.

20. Merskey, C., G. J. Kleiner, and A. J. Johnson. 1966. Quantitative estimation of split products of fibrinogen in human serum, relation to diagnosis and treatment. Blood. 28: 1-18.

21. Monkhouse, F. C. 1963. The influence of inorganic salts on plasma antithrombin activity. Thromb. Diath. Haemorrh. 9: 387-394.

22. Tocantins, L. M. 1964. Estimation of prothrombin (Onestage method of Quick). In Blood Coagulation, Hemorrhage and Thrombosis. L. M. Tocantins and L. A. Kazal, editors. Grune \& Stratton, Inc., New York. 148-150.

23. Matsuda, T. 1967. Coagulation studies on strokes. Nihon Rinsho. 34: 72-78.

24. Highsmith, R. F., and R. D. Rosenberg. 1974. The inhibition of human plasmin by human antithrombin-heparin cofactor. J. Biol. Chem. 249: 4335-4338.

25. Amesen, H., and M. K. Fagerhol. 1972. $\alpha_{2}$-Macroglobulin, $\alpha_{1}$-antitrypsin, and antithrombin III in plasma and serum during fibrinolytic therapy with urokinase. Scand. J. Clin. Lab. Invest. 29: 259-263.

26. Niléhn, J-E., and P. O. Ganrot. 1967. Plasmin, plasmin inhibitors and degradation products of fibrinogen in human serum during and after intravenous infusion of streptokinase. Scand. J. Clin. Lab. Invest. 20: 113-121.

27. Fischer, M. 1971. Influence of thrombolytic therapy on human antiplasmins. Thromb. Diath. Haemorrh. 47 (Suppl.): 153-157.

28. Spöttl, F., and F. Holzknecht. 1970. The influence of inhibitors of plasmin and plasminogen activation on the streptokinase-induced fibrinolytic state. Thromb. Diath. Haemorrh. 24: 100-112.

29. Collen, D., F. De Cock, and M. Verstraete. 1975. Immunochemical distinction between antiplasmin and alpha ${ }_{1}$-antitrypsin. Thromb. Res. 7: 245-249.

30. Müllertz, S. 1974. Different molecular forms of plasminogen and plasmin produced by urokinase in human plasma and their relation to protease inhibitors and lysis of fibrinogen and fibrin. Biochem. J. 143: 273-283.

31. Hedner, U. 1973. Studies on an inhibitor of plasminogen activation in human serum. Thromb. Diath. Haemorrh. 30: 414-424.

32. Mui, P. T. K., H. L. James, and P. Ganguly. 1975. Isolation and properties of a low molecular weight antiplasmin of human blood platelets and serum. $\mathrm{Br} . \mathrm{J}$. Haematol. 29: 627-637.

33. Gallimore, M. J. 1975. Serum inhibitors of fibrinolysis. Br. J. Haematol. 31: 217-231.

34. Hedner, U., and D. Collen. 1976. Immunochemical distinction between the inhibitors of plasminogen activation and antiplasmin in human plasma. Thromb. Res. 8: 875-879.

35. Edy, J., F. De Cock, and D. Collen. 1976. Inhibition of plasmin by normal and antiplasmin-depleted human plasma. Thromb. Res. 8: 513-518.

36. Laurell, C. B. 1972. Electroimmunoassay. Scand. J. Clin. Lab. Invest. 29 (Suppl. 124): 21-37.

37. Ganrot, P. O. 1972. Crossed immunoelectrophoresis. Scand. J. Clin. Lab. Invest. 29 (Suppl. 124): 39-47. 